\title{
PERBANDINGAN ANTARA MODEL AUTOREGRESSIVE INTEGRATED MOVING AVERAGE (ARIMA) DAN MODEL FUNGSI TRANSFER PADA PERAMALAN CURAH HUJAN DI KABUPATEN MANOKWARI
}

\author{
The Comparison between Autoregressive Integrated Moving Average (ARIMA) and Multi \\ Input Transfer Function Models for Rainfall Forecasting \\ in Manokwari Regency
}

Esther Ria Matulessy

Jurusan Matematika dan Statistika Fakultas MIPA, Universitas Papua

email: e.matulessy@unipa.ac.id

\begin{abstract}
This study discusses the comparison of forecasting time series data between the Autoregressive Integrated Moving Average (ARIMA) method and the multi input transfer function model. ARIMA method is one of the most frequently used methods for forecasting time series data. Meanwhile, the transfer function model is a combination of the characteristics of multiple regression analysis with the characteristics of the ARIMA time series. Meanwhile, the multi input transfer function model is a transfer function model that has input variables of more than two time series. The application of these two methods is carried out on rainfall data from January 2012 to December 2017 in Manokwari Regency, West Papua Province. The input variables used are temperature, humidity, solar radiation, air pressure, and wind speed variables. The results showed the best ARIMA model was ARIMA $(1,0,0)(2,0,0) 12$ with an AIC value of 910.07, while for the best multi input transfer function model was ARIMA $(1,1,0)$ AIC value of 898.24. Between the two methods, the best model used to forecast rainfall in Manokwari Regency, West Papua Province is the multiinput transfer function model $(1,1,0)$.
\end{abstract}

Keywords : Forecasting; ARIMA; Multi Input Transfer Function; Rainfall.

\begin{abstract}
ABSTRAK
Penelitian ini membahas mengenai perbandingan peramalan data runtun waktu antara metode Autoregressive Integrated Moving Average (ARIMA) dengan model fungsi transfer multi input. Metode ARIMA merupakan salah satu metode yang paling sering digunakan untuk peramalan data runtun waktu. Sedangkan, model fungsi transfer merupakan gabungan dari karakteristik analisis regresi berganda dengan karakteristik runtun waktu ARIMA. Sementara itu, model fungsi transfer multi input merupakan model fungsi transfer yang memiliki variabel input lebih dari dua deret runtun waktu. Penerapan kedua metode ini dilakukan pada data curah hujan dari bulan Januari tahun 2012 sampai bulan Desember tahun 2017 di Kabupaten Manokwari, Provinsi Papua Barat. Adapun variabel input yang digunakan adalah variabel suhu, kelembapan, penyinaran matahari, tekanan udara, dan kecepatan angin. Hasil penelitian menunjukkan untuk model ARIMA terbaik adalah ARIMA $(1,0,0)(2,0,0)^{12}$ dengan nilai AIC sebesar 910.07, sedangkan untuk model fungsi transfer multi input terbaik adalah ARIMA(1,1,0) nilai AIC sebesar 898.24. Diantara kedua metode, model terbaik yang digunakan untuk meramalkan curah hujan Kabupaten Manokwari Provinsi Papua Barat adalah model fungsi transfer multi input ARIMA $(1,1,0)$.
\end{abstract}

Katakunci : Peramalan; ARIMA; Fungsi Transfer Multi Input; Curah Hujan. 


\section{PENDAHULUAN}

Runtun waktu (time series) merupakan serangkaian data pengamatan yang terjadi berdasarkan indeks waktu secara berurutan dengan interval waktu tetap. Analisis runtun waktu adalah salah satu prosedur statistika yang diterapkan untuk meramalkan struktur probabilistik keadaan yang akan terjadi di masa yang akan datang dalam rangka pengambilan keputusan. Tujuan analisis runtun waktu diantaranya untuk meramalkan kondisi masa yang akan datang (forecasting), mengetahui hubungan antar peubah, mengetahui apakah proses terkendali atau tidak (kepentingan kontrol) (Aswi dan Sukarna, 2006). Beberapa model yang biasa digunakan dalam analisis runtun waktu adalah model Moving Average (MA), model Exponential Smoothing, dan model Autoregressive Integrated Moving Average (ARIMA). Data runtun waktu yang digunakan untuk peramalan haruslah stasioner. Namun, dalam kenyataannya data runtun waktu yang stasioner jarang sekali dijumpai dalam praktiknya. Stasioneritas merupakan asumsi yang sangat penting dalam analisis runtun waktu. Ketidakstasioneran dalam rata-rata dapat diminimalisir pengaruhnya dengan melakukan pembedaan (differencing). Kestasioneran dalam rata-rata dapat dilihat menggunakan uji ADF (Augmented Dickey-Fuller), sedangkan kestasioneran dalam ragam dapat dideteksi dengan menggunakan uji BoxCox. Apabila kestasioneran dalam ragam tidak terpenuhi dapat dilakukan transformasi pada data.

Metode ARIMA (Autoregressive Integrated Moving Average) atau dikenal dengan metode Box-Jenkins merupakan metode yang sering digunakan d alam analisis runtun waktu karena penerapan yang mudah dan ekonomis dengan hasil ramalan yang cukup baik untuk jangka pendek (Abdullah, 2012). Model ARIMA terdiri dari dua aspek, yaitu aspek autoregressive dan moving average (rata-rata bergerak). Secara umum, model ARIMA dituliskan dengan notasi ARIMA $(\mathrm{p}, \mathrm{d}, \mathrm{q})$, dimana $\mathrm{p}$ menyatakan orde dari proses autoregressive (AR), d menyatakan pembedaan (differencing), dan $\mathrm{q}$ menyatakan orde dari proses moving average (MA). Selain itu, terdapat juga model ARIMA musiman untuk runtun waktu musiman. Runtun waktu musiman adalah runtun waktu yang mempunyai sifat berulang setelah beberapa periode waktu tertentu, misalnya satu tahun, satu bulan, triwulan, dan seterusnya. ARIMA musiman secara umum dinotasikan dengan ARIMA $(p, d, q)(P, D, Q)^{S}, \quad$ dimana $P$ 
menyatakan orde dari proses autoregressive (AR) musiman, D menyatakan pembedaan (differencing)

Model autoregressive atau ARIMA $(1,0,0)$ merupakan model yang menggambarkan hubungan antara peubah terikat $\mathrm{Y}$ dengan peubah bebas yang merupakan nilai $\mathrm{Y}$ pada waktu sebelumnya, model moving average atau ARIMA $(0,0,1)$ merupakan model yang menggambarkan ketergantungan peubah terikat $\mathrm{Y}$ terhadap nilai-nilai galat pada waktu sebelumnya yang berurutan, model autoregressive moving average atau ARIMA $(1,0,1)$ merupakan model runtun waktu stasioner yang menggabungkan model AR dengan model MA, dan model autoregressive integrated moving average/ARIMA $(1,1,1)$ merupakan kombinasi model AR dan MA yang telah dijadikan stasioner dengan cara differencing (Aswi dan Sukarna, 2006). Dalam pemodelan runtun waktu ARIMA asumsi yang harus dipenuhi yaitu stasioneritas data dan residual yang bersifat white noise. White noise berarti residual tidak berautokorelasi dan berdistribusi normal (Hidayah et al., 2015).

Model fungsi transfer merupakan salah satu model runtun waktu yaitu gabungan pendekatan regresi dan runtun waktu (ARIMA) untuk error-nya. Dalam fungsi transfer, terdapat deret berkala musiman, dan $\mathrm{Q}$ menyatakan orde dari proses moving average (MA) musiman (Chatfield, 2004).

output yang disebut $\mathrm{Y}_{\mathrm{t}}$, yang diperkirakan akan dipengaruhi oleh satu atau lebih deret berkala input yang disebut $\mathrm{X}_{\mathrm{t}}$, dan input-input lain yang akan digabungkan dalam satu kelompok yang disebut gangguan (noise) dengan symbol $\mathrm{n}_{\mathrm{t}}$. Dengan kata lain, deret input $\mathrm{X}_{\mathrm{t}}$ memberikan pengaruhnya kepada deret output $Y_{t}$ melalui fungsi transfer, yang mendistribusikan dampak $X_{t}$ melalui beberapa periode waktu yang akan datang. Tujuan pemodelan fungsi transfer adalah untuk menetapkan model yang sederhana, yang menghubungkan $Y_{t}$ dengan $X_{t}$ dan $\mathrm{n}_{\mathrm{t}}$. Sehingga dapat disimpulkan bahwa tujuan utama pemodelan jenis ini adalah untuk menetapkan peranan indikator penentu (leading indicator) atau deret input dalam rangka menetapkan variabel yang dibicarakan (deret output) (Makridakis et al., 1999).

Tahapan dalam pemodelan fungsi transfer multi input untuk deret input $\left(\mathrm{X}_{\mathrm{t}}\right)$ dan deret output $\left(\mathrm{Y}_{\mathrm{t}}\right)$ adalah dengan cara mengidentifikasi deret input tunggal terlebih dahulu supaya mendapatkan orde model ARIMA. Setelah didapatkan model ARIMA untuk deret input tunggal dan deret output, selanjutnya dilakukan pemutihan dan perhitungan korelasi silang 
untuk masing-masing deret input dengan output yang berguna untuk menentukan nilai $\mathrm{r}$, s, dan $\mathrm{b}$ untuk model fungsi transfer (Makridakis et al., 1999). Beberapa aturan yang dapat digunakan untuk menduga nilai $\mathrm{r}, \mathrm{s}$, dan $\mathrm{b}$ dari suatu fungsi transfer: Nilai $b$ menyatakan $Y_{t}$ idak terpengaruh oleh $X_{t}$ sampai periode $\mathrm{t}+\mathrm{b}$. Besarnya $\mathrm{b}$ dapat ditentukan dari lag yang pertama kali pada plot korelasi silang. Nilai s menyatakan seberapa lama deret $Y_{t}$ terus dipengaruhi atau bilangan pada lag plot korelasi silang sebelum terjadinya pola menurun. Nilai $r$ menyatakan bahwa $\mathrm{Y}_{\mathrm{t}}$ dipengaruhi oleh nilai masa lalunya, bila ada beberapa lag plot pada korelasi silang yang terpotong (Wei, 2005). Setelah nilai r, s, b ditentukan, kemudian dilakukan identifikasi bentuk model fungsi transfer dan noise-nya. Selanjutnya akan dilakukan estimasi parameter dan uji diagnostik sehingga akhirnya didapatkan model fungsi transfernya (Makridakis et al., 1999).

Pemilihan model terbaik dipilih dengan melihat nilai AIC (Akaike Information Criterion) dan nilai MAPE (Mean Absolute Percentage Error) terkecil. AIC adalah suatu kriteria pemilihan model terbaik yang diperkenalkan oleh Akaike pada tahun 1973 dengan mempertimbangkan banyaknya parameter dalam model. Sedangkan, besarnya nilai MAPE menunjukkan data hasil peramalan semakin mendekati nilai aktual (Wei, 2006).

Iklim berperan besar dalam kehidupan manusia seperti pada bidang pertanian, transportasi, telekomunikasi, dan pariwisata. Curah hujan sebagai unsur iklim yang paling tinggi fluktuasinya dan paling dominan mencirikan iklim di Indonesia sangat dipengaruhi oleh perubahan iklim global. Curah hujan merupakan ketebalan air hujan yang terkumpul pada luasan $1 \mathrm{~m}^{2}$. Curah hujan dihitung dengan satuan $\mathrm{mm}$ (milimeter), yaitu tinggi air yang tertampung pada area seluas $1 \mathrm{~m}^{2}$. Rata-rata curah hujan di Indonesia cukup tinggi, yaitu sekitar 2.000 $\mathrm{mm} /$ tahun. Hal ini disebabkan wilayah Indonesia terletak di daerah tropis. Oleh sebab itu, iklim di Indonesia adalah tropis lembab, yaitu iklim tropis yang banyak mengandung uap air, rata-rata curah hujan yang tinggi berpengaruh terhadap sebagian besar mata pencaharian penduduk (BMKG,2017). Peramalan curah hujan dapat menggunakan analisis deret waktu.

\section{METODE PENELITIAN}

Data yang digunakan dalam penelitian ini adalah data curah hujan 
bulanan Kabupaten Manokwari yang diperoleh dari Badan Meteorologi Klimatologi dan Geofisika (BMKG) Kabupaten Manokwari. Variabel pada data terdiri dari variabel curah hujan,suhu, kelembapan, penyinaran matahari, tekanan udara, dan kecepatan angin tahun 2012 2017. Analisis data dalam penelitian ini menggunakan software RStudio. Langkahlangkah proses analisis data yang dilakukan pada penelitian ini yaitu:

1. Membuat plot data runtun waktu untuk variabel curah hujan.

2. Melakukan pemodelan ARIMA untuk setiap variabel curah hujan, suhu, kelembapan, penyinaran matahari, tekanan udara, dan kecepatan angin.

3. Melakukan pemodelan fungsi transfer multi input, dimana variabel curah

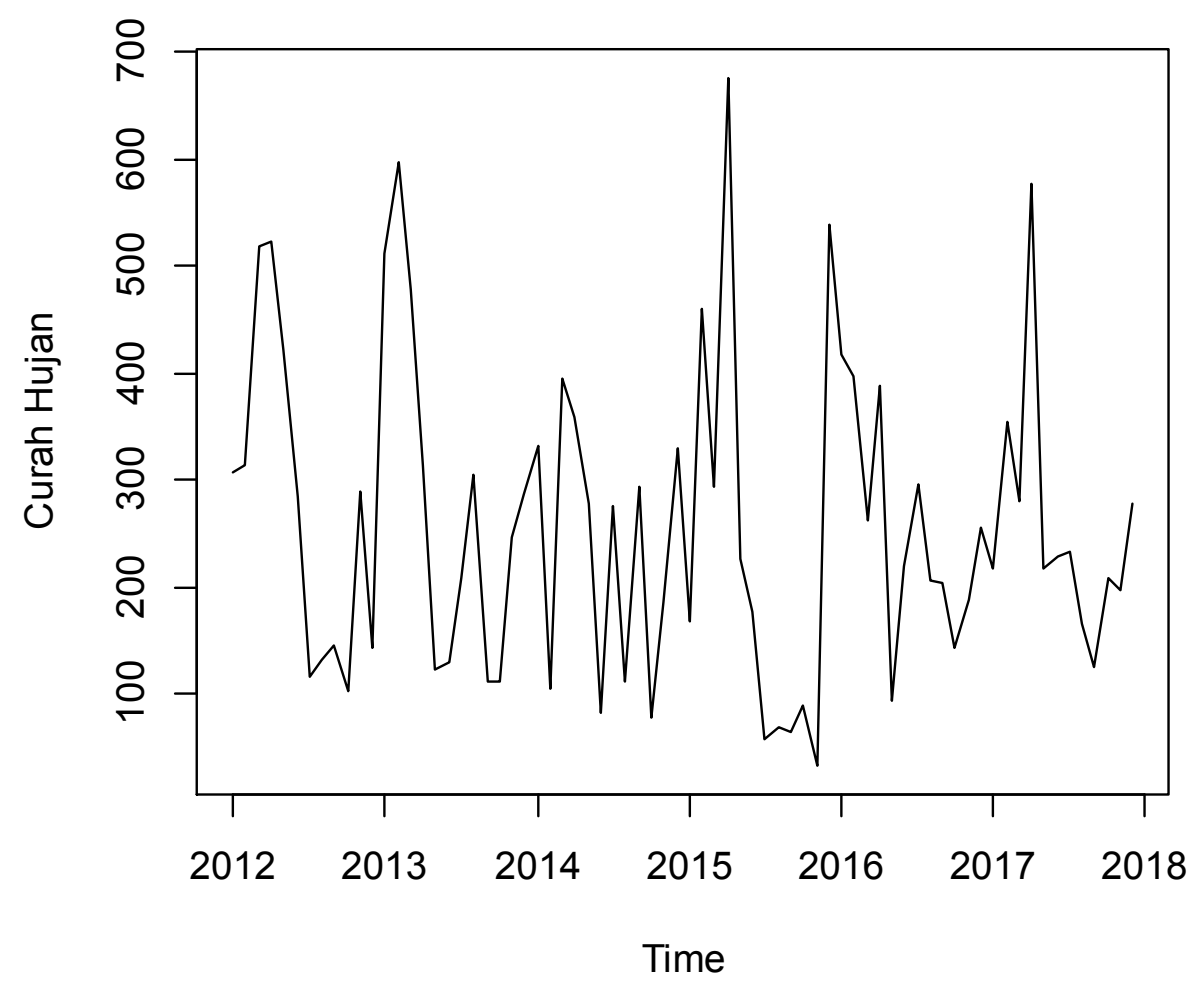

Gambar 1. Plot Data Curah Hujan di Kabupaten Manokwari periode tahun 2012-2017. hujan sebagai deret output, sedangkan variabel suhu, kelembapan, penyinaran matahari, tekanan udara, dan kecepatan angin sebagai deret input.

4. Membandingkan model ARIMA dan model fungsi transfer multi input dengan memilih model terbaik berdasarkan nilai AIC dan MAPE terkecil.

5. Melakukan peramalan curah hujan Januari 2018 - Desember 2018 menggunakan model terbaik yang diperoleh dari tahap sebelumnya.

\section{HASIL DAN PEMBAHASAN}

Plot data curah hujan di Kabupaten Manokwari periode tahun 2012 - 2017 dapat dilihat pada Gambar 1. 
Hasil pengujian stasioneritas dalam rata-rata terhadap data curah hujan bulanan Kabupaten Manokwari menggunakan metode ADF (Augmented Dickey-Fuller) diperoleh bahwa data curah hujan bulanan Kabupaten Manokwari telah stasioner dalam rata-rata, hal ini ditunjukkan dengan nilai probabilitas < 0,05 dan nilai ADF sebesar -5,643.

Pengujian stasioneritas dalam ragam pada data curah hujan bulanan Kabupaten Manokwari menggunakan Uji Box-cox. Nilai lambda sebesar 1 pada Uji Box-Cox menunjukkan bahwa data curah hujan bulanan telah stasioner dalam ragam dan tidak perlu ditransformasi.

\section{Pemodelan ARIMA Curah Hujan}

Berdasarkan uji kesesuaian model yang terdiri dari uji asumsi white noise dan uji asumsi normalitas residual, model yang memenuhi kriteria untuk dapat dijadikan model terbaik untuk data curah hujan adalah model ARIMA $(1,0,0)(2,0,0)^{12}$ dengan nilai AIC sebesar 910,07 dan nilai MAPE sebesar 59,682.

\section{Pemodelan ARIMA Suhu}

Berdasarkan uji kesesuaian model yang terdiri dari uji asumsi white noise dan uji asumsi normalitas residual, model yang memenuhi kriteria untuk dapat dijadikan model terbaik untuk data suhu adalah model ARIMA $(2,1,0)(1,1,0)^{12}$ dengan nilai AIC sebesar 283,85 dan nilai MAPE sebesar 0,08.

\section{Pemodelan ARIMA Kelembapan}

Berdasarkan uji kesesuaian model yang terdiri dari uji asumsi white noise dan uji asumsi normalitas residual, model yang memenuhi kriteria untuk dapat dijadikan model terbaik untuk data kelembapan adalah model ARIMA $(1,0,0)$ dengan nilai AIC sebesar 49,33 dan nilai MAPE sebesar 1,536.

\section{Pemodelan ARIMA Penyinaran Matahari}

Berdasarkan uji kesesuaian model yang terdiri dari uji asumsi white noise dan uji asumsi normalitas residual, model yang memenuhi kriteria untuk dapat dijadikan model terbaik untuk data penyinaran matahari adalah model ARIMA $(1,0,0)(1,1,0)^{12}$ dengan nilai AIC sebesar 449,51 dan nilai MAPE sebesar 12,121 .

\section{Pemodelan ARIMA Tekanan Udara}

Berdasarkan uji kesesuaian model yang terdiri dari uji asumsi white noise dan uji asumsi normalitas residual, model yang memenuhi kriteria untuk dapat dijadikan model terbaik untuk data tekanan udara adalah model ARIMA $(2,0,0)(1,1,0)^{12}$ dengan nilai AIC sebesar 123,23 dan nilai MAPE sebesar 0,059. 


\section{Pemodelan ARIMA Kecepatan Angin}

Berdasarkan uji kesesuaian model yang terdiri dari uji asumsi white noise dan uji asumsi normalitas residual, model yang memenuhi kriteria untuk dapat dijadikan model terbaik untuk data kecepatan angin adalah model ARIMA $(1,1,1)$ dengan nilai AIC sebesar 141,13 dan nilai MAPE sebesar 18,669.

\section{Pemodelan Fungsi Transfer Multi Input}

Seluruh parameter telah signifikan berbeda dengan nol dan memenuhi pemeriksaan diagnostik yaitu kenormalan residual dan pengujian white noise. Maka, selanjutnya membentuk korelasi silang dari antara deret input dan deret output yang telah diputihkan. Korelasi silang antara deret output (curah hujan) dan deret input (suhu) menghasilkan nilai $\mathrm{r}=$ $0, \mathrm{~s}=0$, dan $\mathrm{b}=3$, korelasi silang antara deret output (curah hujan) dan deret input (kelembapan) menghasilkan nilai $\mathrm{r}=0, \mathrm{~s}$ $=0$, dan $\mathrm{b}=0$, korelasi silang antara deret output (curah hujan) dan deret input (penyinaran matahari) menghasilkan nilai $\mathrm{r}=0, \mathrm{~s}=0$, dan $\mathrm{b}=4$, korelasi silang antara deret output (curah hujan) dan deret input (tekanan udara) menghasilkan nilai $\mathrm{r}=0, \mathrm{~s}=0$, dan $\mathrm{b}=0$, dan korelasi silang antara deret output (curah hujan) dan deret input (kecepatan angin) menghasilkan nilai $\mathrm{r}=0, \mathrm{~s}=0$, dan $\mathrm{b}=$ 13. Kemudian dilakukan pemodelan untuk deret noise dari masing-masing korelasi silang yang diperoleh pada tahap sebelumnya. Model yang diperoleh untuk masing-masing deret noise yang telah memenuhi pemeriksaan diagnostik yaitu kenormalan residual dan pengujian white noise adalah $\operatorname{ARMA}(0,0)$. Tahapan terakhir, diperoleh model fungsi transfer multi input $(1,1,0)$ sebagai model terbaik dengan nilai AIC sebesar 900,84 dan nilai MAPE sebesar 51,995. Hasil estimasi parameter ditunjukkan pada Tabel 1.

Parameter PM, TU, dan KA tidak signifikan, oleh karena itu variabel $\mathrm{X}_{3}$, $\mathrm{X}_{4}$, dan $\mathrm{X}_{5}$ dikeluarkan satu per satu sampai diperoleh model dengan semua parameter signifikan. Tabel 2 menunjukkan hasil estimasi parameter akhir model fungsi transfer multi input.

Tabel 1. Hasil Estimasi Parameter Model Fungsi Transfer Multi Input $(1,1,0)$

\begin{tabular}{lrcccc}
\hline \multicolumn{1}{c}{ Parameter } & \multicolumn{1}{c}{ Estimasi } & p-Value & Lag & Variabel & Shift \\
\hline $\mathrm{AR}_{1}$ & $-0,471$ & 0,000 & 1 & $\mathrm{Y}$ & 0 \\
Suhu & $-155,480$ & 0,002 & 0 & $\mathrm{X}_{1}$ & 3 \\
Kelembapan & 27,571 & 0,008 & 0 & $\mathrm{X}_{2}$ & 0 \\
$\mathrm{PM}$ & 1,948 & 0,366 & 0 & $\mathrm{X}_{3}$ & 4 \\
$\mathrm{TU}$ & $-12,165$ & 0,566 & 0 & $\mathrm{X}_{4}$ & 0 \\
$\mathrm{KA}$ & 17,365 & 0,438 & 0 & $\mathrm{X}_{5}$ & 13 \\
\hline
\end{tabular}


Tabel 2. Hasil Estimasi Parameter Akhir Model Fungsi Transfer Multi Input $(1,1,0)$

\begin{tabular}{lrcccc}
\hline \multicolumn{1}{c}{ Parameter } & Estimasi & $\mathrm{p}$-Value & Lag & Variabel & Shift \\
\hline $\mathrm{AR}_{1}$ & $-0,470$ & 0,000 & 1 & $\mathrm{Y}$ & 0 \\
Suhu & $-137,348$ & 0,000 & 0 & $\mathrm{X}_{1}$ & 3 \\
Kelembapan & 22,098 & 0,009 & 0 & $\mathrm{X}_{2}$ & 0 \\
\hline
\end{tabular}

Nilai AIC yang diperoleh sebesar 898,24 dan nilai MAPE sebesar 55,253. Berdasarkan pemeriksaan diagnostik model fungsi transfer, model yang diperoleh telah memenuhi asumsi kenormalan residual, tidak terdapat autokorelasi residual, dan tidak terdapat korelasi antara deret noise dan deret input.

\section{Pemilihan Model Terbaik}

Model terbaik dipilih berdasarkan nilai AIC dan nilai MAPE terkecil. Tabel 3 menunjukkan perbandingan model ARIMA dengan model fungsi transfer multi input.

Model terbaik yang ditunjukkan oleh AIC, AICc, BIC dan MAPE terkecil adalah model fungsi transfer multi input $(1,1,0)$. Berdasarkan model terbaik, maka hasil peramalan curah hujan ditunjukkan pada Tabel 4.

Tabel 3. Perbandingan Model ARIMA dan Model Fungsi Transfer Multi Input

\begin{tabular}{ccccc}
\hline Model & AIC & AICc & BIC & MAPE \\
\hline ARIMA $(1,0,0)(2,0,0)^{12}$ & 910.07 & 910.97 & 921.45 & 59.682 \\
& & & & \\
Fungsi Transfer Multi Input (1,1,0) & 898.24 & 898.85 & 907.29 & 55.253 \\
\hline
\end{tabular}

Tabel 4. Hasil Peramalan Curah Hujan bulan Januari 2018 - Desember 2018.

\begin{tabular}{lc}
\hline \multicolumn{1}{c}{ Bulan } & Hasil Peramalan $(\mathrm{mm})$ \\
\hline Januari & 359,212 \\
Februari & 311,393 \\
Maret & 407,689 \\
April & 435,048 \\
Mei & 292,237 \\
Juni & 304,143 \\
Juli & 303,597 \\
Agustus & 232,188 \\
September & 226,696 \\
Oktober & 113,883 \\
November & 284,656 \\
Desember & 320,501 \\
\hline
\end{tabular}


Tabel 4 memperlihatkan nilai hasil peramalan curah hujan untuk Januari 2018 sampai dengan Desember 2018, memiliki curah hujan tertinggi pada bulan April yaitu sebesar 435,048 mm. Kemudian curah hujan terendah terjadi pada bulan Oktober sebesar 113,883 mm.

\section{KESIMPULAN}

1. Model ARIMA terbaik dari data curah hujan Kabupaten Manokwari adalah model ARIMA $(1,0,0)(2,0,0)^{12}$ dengan nilai AIC sebesar 910,07 dan nilai MAPE sebesar 59,682.

2. Model fungsi transfer multi input terbaik dari data curah hujan Kabupaten Manokwari adalah model fungsi transfer multi input $(1,1,0)$ dengan nilai AIC sebesar 898,24 dan nilai MAPE sebesar 55,253.

3. Perbandingan model ARIMA dan fungsi transfer multi input menunjukkan model terbaik curah hujan yaitu model fungsi transfer multi input $(1,1,0)$. Adapun hasil peramalan curah hujan untuk bulan Januari 2018 sampai Desember 2018 diperoleh curah hujan tertinggi pada bulan bulan April yaitu sebesar 435,048 $\mathrm{mm}$ dan curah hujan terendah terjadi pada bulan Oktober sebesar 113,883 mm.

\section{DAFTAR PUSTAKA}

Aswi dan Sukarna. 2006. Analisis Deret Waktu: Teori dan Aplikasi. Makassar: Andira Publisher.

Abdullah, L. 2012. ARIMA Model for Gold Bullion Coin Selling Prices Forecasting. International Journal of Advances in Appllied Sciences (IJAAS). 1(4):153-158. ISSN 22528814.

[BPS] Badan Pusat Statistik.2013. Kabupaten Manokwari Dalam Angka.

https://manokwarikab.bps.go.id/ [6 Juni 2019]

[BPS] Badan Pusat Statistik.2014. Kabupaten Manokwari Dalam Angka. https://manokwarikab.bps.go.id/ [6 Juni 2019]

[BPS] Badan Pusat Statistik.2015. Kabupaten Manokwari Dalam Angka.

https://manokwarikab.bps.go.id/ [6 Juni 2019]

[BPS] Badan Pusat Statistik.2016. Kabupaten Manokwari Dalam Angka.

https://manokwarikab.bps.go.id/ [6 Juni 2019]

[BPS] Badan Pusat Statistik.2017.Kabupaten

Manokwari Dalam Angka. https://manokwarikab.bps.go.id/ [6 Juni 2019]

[BPS] Badan Pusat Statistik.2018. Kabupaten Manokwari Dalam Angka.

https://manokwarikab.bps.go.id/ [6 Juni 2019]

Chatfield, C. 2004. The Analysis of Times Series An Introduction. Florida: CRC Press Company.

Hidayah, Siti L. I. A., Rusgiyono, Agus., dan Wilandari, Yuciana. 2015. Perbandingan Model ARIMA dan Fungsi Transfer pada Peramalan Curah Hujan Kabupaten Wonoboso. Jurnal Gaussian. 4(4): 1037-1044. 
Makridakis S., Wheelwright, S.C. dan V.E. McGee. 1999. Metode dan Aplikasi Peramalan. Terjemahan Hari Suminto. Jilid I. Edisi II. Jakarta: Bina Rupa Aksara.

Wei, W.S William. 2005. Time Series Analysis Univariate and Multivariate Methods. California: Addison Wesley Publishing Company. 